\title{
ON THE DELAMINATION SUPPRESSION IN STRUCTURAL JOINTS BY Z-FIBRE PINNING
}

\author{
G. Allegri, X. Zhang \\ School of Engineering, Cranfield University, Bedfordshire, MK43 OAL, England
}

\begin{abstract}
The main objective of this paper is to investigate the benefits of Z-fibre pinning to improve the bonding strength of composite joints. The problem is addressed from a design point of view in order to develop a simulation methodology that can be employed to predict the strength of Z-fibre pinned joints. Firstly, an efficient and accurate computational approach is presented using the well established finite element method in conjunction with a constitutive model of Z-fibre response behaviour under mixed mode loading condition. The Z-fibre bridging model previously developed by the authors is summarised in the paper. Secondly, the computational approach is demonstrated via the analysis of two structural joints, namely a conventional T-joint and a novel cruciform joint. Comparison with test data confirms the model's predictive capability.
\end{abstract}

\section{Keywords}

(A) 3-Dimensional reinforcement (B); Damage Tolerance; (B) Debonding; (C) FEA; Adhesively bonded joints

\section{Introduction}

Currently composite structures are joined by either mechanical fastening or adhesive bonding. The integrity of a structure is critically dependent on these structural joints. For bolted joints the highly concentrated stresses at fastener holes and the free edge effect will initiate fatigue damage [1]. The subsequent crack growth may appear as both in-plane fractures and out-of-plane delaminations, depending essentially on the laminate thickness [2]; relatively thin composite plates are affected by inplane cracking, while thick shells are prone to cumulated interlaminar damage in the form of distributed delaminations.

Better damage tolerance performances is usually achieved by adhesively bonded joints, since the continuity of the fibres is not broken by fastening holes and in-plane fatigue crack growth is prevented [3]. However solely bonded joints are susceptible to out-of-plane damage in the form of delamination and disbond; this is the consequence of the relatively weak interlaminar strength of conventional adhesive joints [4].

Through-thickness reinforcement has been proved to be an effective way to prevent or retard delamination growth by improving the interlaminar strength [5]. The reinforcement can be applied in the form of small diameter pins, stitches, or 3D interlocked fabrics. The physics ruling the improved out-of-plane load bearing capability is complex and dependent on the specific type of reinforcement.

This paper focuses on Z-fibre reinforced (or z-pinned) joints. The technique is applied by inserting small diameter metallic or fibrous pins in the thickness direction, i.e. the local laminate " $Z$ " axis. The insertion is performed on uncured laminates with an ultrasonic gun; it is a relatively low-cost process 
[6]. Z-pin insertion slightly affects the in-plane mechanical properties of composite laminates. For example, a 10 to 15 per cent loss of in-plane mechanical properties is found in pinned laminates, but the out-of-plane stiffness is significantly increased by $25 \%$ [7]. The in-plane elastic properties are dependent on Z-fibre diameter and volumetric density, but less dependent on the laminate stacking sequence.

Extensive experimental campaign has been carried out to asses the damage tolerance capability of Zfibre reinforced composite laminates; the positive influence of reinforcing Z-fibres on delamination growth has been assessed by testing standard DCB, MMB, lap and T-joint specimens [8-10] demonstrating much improved damage tolerance capabilities. All types of through-thickness reinforcement delay delamination growth by bridging forces that constraint the crack opening displacements [11]. The bridging actions can be described by constitutive laws relating the crack opening displacements to the traction forces which arise in the crack wake [12].

Several researchers have worked on formulating Z-fibre constitutive laws and its applications in simulation. Cox and Sridhar [13] developed an analytical micro-mechanical model for mixed-mode loading condition; the constitutive relation of through-thickness reinforcement is obtained in the form of non-linear implicit function relating the crack opening displacements to the bridging forces. Yan et al. [14-15] performed FE analysis of delamination growth in Z-fibre reinforced DCB and ENF specimens, under modes I and II conditions, respectively. The constitutive model of Z-pins is described by an empirical load vs. displacement curve, obtained by fitting experimental data of single pin pullout test. A similar approach was employed also by Cartie and Partridge [16]. Recently, empirical bi-linear constitutive law has been employed by Ratcliffe and O'Brien [17] for predicting the mechanical response of Z-fibre reinforced DCB specimens, in which an empirical Z-pin bridging law was incorporated into an analytical model of DCB employing the classical beam theory. A similar problem was studied by Grassi and Zhang [18] by FEA implementing the Cox and Sridhar model. All aforementioned work has studied the original Z-fibre pins having typical diameter of $0.28-0.5 \mathrm{~mm}$, but a recent study has investigated bonding reinforcement by larger diameter pins ( $2 \mathrm{~mm}$ ) inserted into holes drilled through a bonded lap joint section [19]. Significant gains were demonstrated in ultimate strength and resistance to debond growth, and the modelling technique was successful.

This paper presents an efficient design tool using the FEM for Z-fibre reinforced composite joints. A constitutive model for Z-fibre mechanical response has been developed by the authors [20], which has the main advantage of being fully analytical and explicit, thus its implementation into a commercial FE package is largely simplified. The computational approach is validated by experimental test data comprising the response of a standard T-joint and a complex cruciform joint subjected to quasi-static loading regimes.

\section{A mixed mode constitutive model for Z-fibre response}

The qualitative phenomenology of Z-fibre mechanical response is sketched in Fig. 1 showing a single Z-fibre embedded in a composite laminate. Z-fibre's initial position is normal to the laminate plane. 


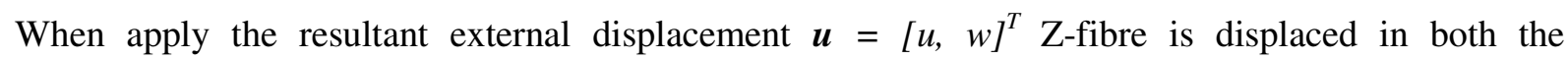
longitudinal $(x)$ direction and the transverse $(z)$ direction. This motion is resisted by a set of forces exerted on the Z-fibre by the surrounding laminate. The vector sum of these forces can be equivalently represented by the stress resultant $\boldsymbol{T}=\left[T_{X}, T_{Z}\right]^{T}$ acting on the Z-fibre section at the delamination plane $z=0$. This resultant also represents the Z-fibre bridging forces that oppose the delamination opening motion and can be described by:

$$
T=T(u)
$$

A constitutive model has been developed by the authors [20] to express equation (1) explicitly. This was achieved by assuming the Z-fibre being a perfectly rigid body embedded in an orthotropic elastic foundation representing the surrounding composite laminate and by establishing and solving a set of equilibrium equations involving all the stresses and displacements. A brief summary of this solution is given below and key equations in Appendix A.

Z-fibre response behaviour is modelled by two distinct stages, i.e. pure elastic deformation of Z-fibre before it debonds from the base laminate and the progressive pullout of Z-fibre. Debond is assumed to occur instantaneously and to mark the transition between the two stages. The pin's rigid movement within the laminate is sketched in Fig. 2, where $L$ is the pin insertion length and $\phi$ the initial insertion angle. The delamination face is identified by the plane $z=0$, and $x$-axis is assumed to be locally tangent to the delamination edge. Due to the external force $\boldsymbol{T}$, each point constituting the pin $(P)$ is subjected to a rigid motion with three components: (1) rigid rotation $\psi$ around the $y$-axis; positive anticlockwise, (2) rigid transversal translation $u_{B}$ along the $\mathrm{x}$-axis, and (3) rigid axial displacement $w_{s l}$ along the pin axis. When Z-fibre is still bonded to the base laminate, the pin only has rigid rotation and $w_{s l}=0$. The axial displacement $w_{s l}$ will occur during the pin pullout stage. Due to these rigid movements point $P$ reaches two intermediate positions, $P^{\prime}$ and $P^{\prime \prime}$, and final position $P^{\prime \prime \prime}$. The summation of the rigid motions is commutative, so the order of the displacements can be permuted by choice.

The base laminate surrounding the pin reacts to the pin's rigid motion by following set of distributed forces: (1) an elastic foundation force $q_{z}$ acting along the $z$-axis opposing the rigid displacement $u$, (2) an elastic foundation force $q_{x}$ acting along the $x$-axis opposing the rigid displacement $w$, and (3) a distributed force $p$ acting on the pin lateral surface, which is necessary to equilibrate the distributed force $q_{z} ; p$ arises because of the interfacial stresses and friction between the Z-fibre lateral surface and the surrounding orthotropic elastic foundation. Fig. 3 qualitatively shows the distributions of these reaction forces acting on the pin in the case of pure mode II loading. It is worth mentioning that a pure mode II loading condition occurs only if the Z-fibre is inserted normally to the delamination plane, i.e. $\phi=0$, and the applied displacement is on the delamination plane, i.e. $w=0$. If the insertion angle is positive or the load is not pure shear the resulting opening process is always a mixed mode one. Mixed mode condition also occurs for a zero insertion angle as soon as the Z-fibre starts to rotate by angle $\psi$. Therefore pure mode II condition hardly exists with respect to the Z-fibre rigid kinematics, since an 
axial force component is always present when an external shear action is applied; the axial force can produce pullout if the cosine value of the angle between the external force and the pin orientation is positive. On the other hand a pure mode I loading condition can occur if the Z-fibre has a zero insertion angle and if the applied external displacement is normal to the delamination plane; in this special condition the model is still valid, but the soil elastic reactions $q_{z}$ and $q_{x}$ are always zero and the pullout is resisted only by the distributed superficial force $p$, which depends on the friction between the Z-fibre lateral surface and the embedding composite laminate.

The key parameters ruling the Z-fibre response are the elastic foundation moduli featuring the embedding laminate $k_{x}$ and $k_{z}$, the half insertion depth $L$, the insertion angle $\phi$, and Z-fibre diameter and volumetric density. See equations in Appendix A. The only unknown parameters which appear in the model equations are the laminate elastic foundation moduli $k_{x}$ and $k_{z}$ and a critical rotation angle for debonding $\psi_{d}$. This latter represents the amount of rigid rotation that must be reached in order to break the adhesive bond between the pin and the embedding laminate so that to start the pullout phase. The mode I opening behaviour is a special case of the general mixed mode response of Z-fibres; the experimental investigation of this particular problem is particularly interesting, since it allows to estimate the role of friction during the Z-fibre pullout regardless to other parameters. On the other hand the investigation of the mode II condition, or mode II dominated mixed mode ones, Z-fibre mechanical response is much more complex, since all aforementioned parameters play significant roles in the bridging law. For a detailed discussion the reader is referred to [20].

The main difference in Z-fibre behaviour between the mode I and mixed mode cases is the amount of energy absorption in the pre-debonding stage: in mode I pre-debonding stage absorbs only $1 \%$ of the total amount of energy spent to extract the Z-fibre from the surrounding laminate; hence it is almost negligible. For mode II or mode II dominated mixed mode condition, the pre-debonding stage expend about $40 \%$ of the total elastic energy. This characteristic behaviour is clearly captured by the present bridging model and supported by experimental evidence $[8,10,20]$.

\section{T-joint pull-off: experimental tests and numerical simulations}

\subsection{Problem statement}

The geometry of the T-joint is sketched in Fig. 4. The joint was made of Hexcel G986/M36 carbon/epoxy fabric pre-preg, whose mechanical properties are reported in Table 1. The supporting base of the joint was made of 8 pre-preg layers, each $0.28 \mathrm{~mm}$ thick, with $\left[0 /(45)_{2} /(0)_{5}\right]$ orientation, resulting in a total thickness $t_{S}=2.24 \mathrm{~mm}$. The flange was fabricated using 10-ply laminate $\left[45 /(0)_{2} /(45)_{2} /(0)_{5}\right]$ of the same material, having a thickness $t_{\mathrm{f}}=2.8 \mathrm{~mm}$. The web was made of the same material with $[0,45]_{\mathrm{S}}$ having thickness $\mathrm{t}_{\mathrm{w}}=1.12 \mathrm{~mm}$. The supported length of the joint is $L=$ $80 \mathrm{~mm}$, the total height $H=40 \mathrm{~mm}$, and the width $W=40 \mathrm{~mm}$. End-tabs were added to the web to provide a proper redistribution of the load applied by the jig. The central core radius of the joint was filled by insertion of a composite filling noodle made of G986/M36 fabric. The flange-to-base bond was reinforced by insertion of T300/BMI Z-pins with variable pin diameter and volumetric density. 
The T-joints were tested by applying a quasi-static tensile load up to the final failure. The failure is due to the delamination growth both in the flange-to-skin bond and in the web adhesive layer; this observation was confirmed by photographic recording of delamination growth and post-failure examinations.

\subsection{Simulation technique}

A numerical procedure has been established to simulate the delaminations growth in the joint. Only one quarter of the joint was modelled due to its $x$ and $z$ symmetries. A detailed 3D FE model of the T-joint was built and analysed by NASTRAN, in which 4-noded laminate shell elements (CQUAD4) were employed to model the structure. Interface "spring" elements (CELAS2) were used to simulate the peel and shear response of the adhesive layer [21] according to the properties given in Table 1. The spring elements act as elastic connections between two bonded laminates which are going to be separated during the debond growth. The elements in the flange-to-skin overlap are square, having an area of $1 \mathrm{~mm}^{2}$. Details can be found in [22].

A set of MATLAB subroutines have been written to manage the simulation of debond initiation and growth process; these subroutines perform post-processing analysis of the FE results by acquiring the values of the spring axial forces and calculating the peel and shear stresses within the adhesive layer. The damage initiation is predicted by the Tsai-Hill failure criterion; when it is satisfied for any set of spring elements, these are automatically deleted from the model, thus simulating the delamination onset.

After damage initiation, the debond growth process is modelled by a fracture mechanics approach: the strain energy release rate (SERR) at the debond tips is calculated by the virtual crack closure technique (VCCT) [23] and a discrete set of springs is removed from the model whenever the energy based criterion is satisfied. The critical values of the mode I and mode II SERR were evaluated by DCB and MMB tests on the G986/M36 composite, yielding $G_{I C}=1250 \mathrm{~J} / \mathrm{m}^{2}, G_{I I C}=1100 \mathrm{~J} / \mathrm{m}^{2}[10]$. Thus the composite employed is considerably tougher than most other commercial CFRP. The FE simulation is displacement-controlled: once a debond initiates, iterative static analyses are performed at constant external displacement, updating the debond geometry until the crack front reaches a stable configuration. In this condition the load and displacement values are saved and the analysis goes on by increasing the applied displacement at a prescribed step. The simulation ends when the flange is completely detached from the supporting base skin.

If the joint is reinforced by Z-pins, then after the local adhesive failure the linear springs are substituted by 1D nonlinear elements (PBUSH1D), whose load-displacement response is governed by the pin's bridging law during the progressive debonding and pullout phases using the model described in Section 2. As already mentioned the value of Z-fibre frictional sliding shear $(\tau)$ can be experimentally assessed by mode I single pin pull-out test. However, in the present study this value was estimated by calibrating the constitutive model with the T-joint experimental load-displacement response against the FE analysis results. 


\subsection{Results and discussion}

Following four different test cases have been simulated:

1. unpinned T-joint (control case);

2. Pinned T-joint (Z-fibre fibre diameter $=0.28 \mathrm{~mm}$, volumetric density $=2 \%$ );

3. Pinned T-joint (Z-fibre fibre diameter $=0.28 \mathrm{~mm}$, volumetric density $=4 \%$ );

4. Pinned T-joint (Z-fibre fibre diameter $=0.50 \mathrm{~mm}$, volumetric density $=2 \%$ ).

The experimental tests have revealed that debonds grow both in the flange-to-skin interface and also in the web adhesive layer. To simplify the simulation two different scenarios were considered, both involving a fixed debond length existing in the web: in case A) the web defect size is $5 \mathrm{~mm}$, and in case B) the defect size is $10 \mathrm{~mm}$. The FE result for the control case is shown in Fig. 5. It is observed that the joint stiffness variation due to the different web defect size is negligible, but using the $5 \mathrm{~mm}$ web defect length the joint failure load and displacement are both significantly underestimated; therefore case B) scenario is employed for the following analyses of pinned joints.

Firstly, the nonlinear behaviour of z-pin pullout during debond growth for this specific material and bonding strength is assessed. A suitable frictional sliding shear $\tau$ in the pin constitutive model was found by calibrating the FE model results with the experimental data: the higher the frictional sliding shear, the slower the flange-to-base debond will grow.

Fig. 6 shows the case using $0.28 \mathrm{~mm}$ Z-fibre and $2 \%$ volumetric density. The FE analysis underestimates the experimental load-displacement response if using $\tau=15 \mathrm{MPa}$. A satisfactory agreement is achieved by increasing the z-pin pullout friction to $30 \mathrm{MPa}$. Adding a $2 \%$ volumetric density of $0.28 \mathrm{~mm}$ diameter pins will increase the ultimate load by about $8 \%$ and the failure displacements by $5 \%$. However, according to the FE analysis z-pinning has very little effect on the damage initiation, which occurred at about $1260 \mathrm{~N}$ (or $2.9 \mathrm{~mm}$ in terms of applied displacement). Comparing to the control case, the pinned joint is more damage tolerant, though the benefit is quite marginal.

The analysis for the $0.28 \mathrm{~mm}$ pin diameter and $4 \%$ volumetric density case is shown in Fig. 7. In this case pinning proves to be very efficient in delaying the flange-to-base debond growth: both the ultimate strength and failure displacement are now increased by about $10 \%$. The FE analysis shows only a small debond propagation after the onset, which once again occurs at the same load level found for the unpinned joint; the failure is less progressive than the previous lower density pinned configuration, but it occurs at higher load and displacement.

Finally the joint pinned with larger pins at $2 \%$ volumetric density is presented in Fig. 8. From a physical point of view, increasing the pin diameter is almost equivalent to raising the frictional sliding shear $\tau$, because the insertion of a larger pin provides a larger displacement for the surrounding laminate, which will react by applying larger residual stress on the pin. So this increase in $\tau$ is beneficial to joint strength. On the other hand a sensible loss of in-plane mechanical properties should be expected, due to the larger local misalignment of the in-plane laminate. A good agreement between 
the FE and experimental results is obtained by increasing the frictional sliding shear to $40 \mathrm{MPa}$ to take into account of the larger pin effect. The resulting effect on the T-joint load-displacement curve is close but somewhat below that achieved by adding $2 \%$ of $0.28 \mathrm{~mm}$ diameter pins. This result is not surprising, since the local bridging forces exerted by the pins are now smeared over a larger area due to the fact that the distance between two adjacent pins is a linear decreasing function of the Z-pin diameter if the volumetric fraction is kept constant.

To summarise Z-pinning are effective in delaying debond growth under mode I loading by increasing the joint ultimate strength and debond crack length. Nevertheless the onset of debond cracks is not influenced by Z-fibre's presence and the larger Z-fibre diameter can have a detrimental effect on the in-plane mechanical properties.

\section{Cruciform Joint: experimental tests and numerical simulation}

\subsection{Problem statement}

In this section the mechanical response of a cruciform composite joint subjected to biaxial tensile loading is presented. The joint consisting of intersecting stiffeners is capable of carrying loads in orthogonal directions and thus can be employed as supporting frames to build integrally-stiffened thin shell structures. Fig. 9 shows a sketch of the novel joint. The joints were manufactured by conventional pre-preg lay-up employing 914/G803 carbon/epoxy fabrics arranged in a $\pm 45^{\circ}$ orientation. The average ply thickness is $0.25 \mathrm{~mm}$. The joint arm length is $250 \mathrm{~mm}$ both in the $x$ and $y$ axis, the web height is $50 \mathrm{~mm}$, the web thickness is $0.5 \mathrm{~mm}$, the top and bottom flange thickness is 1 $\mathrm{mm}$, and the overlapping region thickness is $2 \mathrm{~mm}$. The forces acting on the four arms are exchanged via longitudinal extensions of each upper plate segment, which form a 2 × 2 mosaic on the central "overlapping" area. This arrangement provides additional strength to the whole assembly; conventional cruciform joints are fabricated simply by bonding four " $L$ " shaped plates, so the ultimate strength is merely the adhesive ultimate peel strength multiplied by the contact area. In the orthogonal joint another bonded surface, the overlapping region, is added to the basic design, thus it should increase the ultimate strength. However, since the adhesive layers in the overlapping region work under pure shear loads, this 50 x $50 \mathrm{~mm}$ overlapping region still is a critical area for the joint integrity. Hence, Z-pins were inserted in this region to increase the bonding strength.

\subsection{Simulation Technique}

The simulation strategy employed for the analysis of the cruciform joint is essentially identical to that for the T-joint case, except that the overlapping area susceptible to debond failure is subjected to nearly pure shear action. The general constitutive model for Z-fibre response under mixed mode loads was employed. Due to the structural symmetry only one quarter of the joint was modelled. During the experimental tests a displacement-controlled quasi-static bi-axial tensile load was applied to the joint arms; the load ratio of the $x$ and $y$ axis is $2: 1$.

\subsection{Results and discussion}


An un-pinned "control" and two Z-fibre pinned joints have been tested. Z-fibre density was $4 \%$ in the pinned cases with variable Z-fibre diameter from $0.28 \mathrm{~mm}$ to $0.51 \mathrm{~mm}$. These tests were simulated to provide inside of the stress distribution and failure mechanism. For the $0.28 \mathrm{~mm}$ diameter pin the numerical model predicts the maximum bridging force of $40 \mathrm{~N}$ exerted by each pin at $0.5 \mathrm{~mm}$ crack surface displacement; for the $0.51 \mathrm{~mm}$ diameter pin the maximum bridging force rises to $130 \mathrm{~N}$ at $0.9 \mathrm{~mm}$ crack displacement. The actual bridging force values employed in the FE model depend on the mesh size, since the bridging actions must be scaled by the ratio between the element area and the effective unit cell surface.

The simulation results performed on a quarter model employing the Z-fibre constitutive law [20] are summarized in Fig. 10. It is observed that Z-fibres have very little effect on the initiation and growth of the debonds within the top overlap, since under mode II dominated loading condition quite large crack face displacements must be reached to gain sufficiently high pin bridging forces. Nevertheless debond growth is sensibly delayed at higher load levels; the pinned joints exhibit considerably improved ultimate strength. The $0.51 \mathrm{~mm}$ diameter pins are less effective than the $0.28 \mathrm{~mm}$ ones, since, at the same pin density, the effectively pinned area for the former is less than the latter.

According to the FE analysis, for the unpinned joint the complete debond of the overlapping areas occurred at $18 \mathrm{kN}$ of applied load in the primary load arm (x-axis) which agrees very well with the experimental data for the control case. Failures started from the complete debond of the top overlap followed by a quick in-plane cracking of the web close to the joint centre. This ultimate load increased to $20 \mathrm{kN}$ for the $0.51 \mathrm{~mm}$ pin diameter case and to $22 \mathrm{kN}$ for the $0.28 \mathrm{~mm}$ diameter. The FE analyses revealed a second failure mode, which was also found in the experimental test. This failure occurred at the adhesive bond-lines at the edges of the top overlap. The one-quarter model allows estimating the internal forces transferred from one overlap to the other, since symmetry constraints have been placed along the edges. The forces acting in the primary load direction for an external force $20 \mathrm{kN}$ are beyond $100 \mathrm{~N}$, so tensile stresses about $100 \mathrm{MPa}$ should be attained at the interfaces between the overlapping arms. These tensile stresses are high enough to break the resin bonds at the edges of the overlapping arms, thus leading to the bond-lines failure, which has been actually observed for Z-pinned joints. The bond-line failure does not occur in the un-pinned joint, since the ultimate strength is below $20 \mathrm{kN}$, while it can affect the Z-pinned joints since the ultimate shear strength of the top overlap is increased by pinning. For the Z-fibre reinforced joints the failure occurred just after the bond-lines breakage within the top overlap followed by a quick growth of cracks in the web; the final collapse occurs at around $19 \mathrm{kN}$, very close to the load level predicted by the FE analysis. The delaminated area in the top overlap is smaller than that of the unpinned joint and the experimental evidence supports the simulation results.

\section{Conclusions}

This work presents an FE analysis of two kinds of adhesively bonded composite joints reinforced by Z-fibres. Linear elastic fracture mechanics is applied to evaluate the delamination/debond progression 
in these structural joints under general mixed mode loads. The modelling approach incorporates a post-processing step on the computation of the strain energy release rate at the delamination/debonds fronts and z-fibre bridging forces. The computation is performed in the MATLAB environment employing NASTRAN as the main processor for the FE analysis. The method also incorporates a constitutive model of Z-fibre response under mixed mode loading previously developed by the authors.

The mechanical responses of a composite T-joint and a cruciform joint subjected to tensile static load are employed as benchmark problems to validate the numerical technique for simulating delamination growth in Z-fibre reinforced structural joints. The FE simulation yields satisfactory agreement with the experimental load-displacements curves for the T-joint. The insertion of Z-fibres in the flange-to-skin bond improves the damage tolerance capabilities by increasing both ultimate strength and the failure pull-off displacement. The effects of variable Z-fibre volumetric densities and diameters are correctly predicted. The test demonstrates that Z-fibres are particularly effective in retarding the delamination/debond growth in pure mode I loading; nevertheless it has been also demonstrated that the onset of debond cracks is not influenced by Z-fibre's presence and larger Z-fibre size can have detrimental effect on the in-plane mechanical properties.

The FE analyses have shown that the damage process in the cruciform joint has at least three different failure modes, i.e. delamination of the bonded overlap top region, in-plane failure of the web laminate, and failure of the overlap bond-lines. The delamination growth within the overlap region, which is driven by pure mode II fracture mechanism, is the most critical of the three, since it occurs at a low load level and affects the load distribution in the joint laminate. Both the in-plane crack growth in the web and the bond-line failure occur at relatively high load levels when the overlap head of the joint has been severely debonded. The insertion of Z-fibres in the overlap area significantly retards the debond growth, even though it has no noticeable effect on the other two failure modes; therefore the damage tolerance capability of the cruciform joint is only modestly improved by Z-fibre insertion.

\section{Acknowledgement}

This work was funded by the DTI CARAD programme via the JOINTS project. The authors wish to thank Drs. I.K. Partridge, D.D.R. Cartié and M. Troulis for providing validation experimental data.

\section{References}

[1] Saunders, DS, Galea, SC, Deirmendjian, GK, The development of fatigue damage around fastener holes in thick graphite/epoxy composite laminates. Composites, 1993; 24(4): 309-21.

[2] Chen, W.H., Lee, S.S., Yeh J.T., Three-dimensional contact stress analysis of composite laminate with bolted joint. Composite Structures, 1995; 30(3): 287-97.

[3] Kretsis, G., Matthews, F.L., The strength of bolted joints in glass fibre/epoxy laminates. Composites, 1985; 16(2): 92-102.

[4] Fernlund, G., Spelt, J.K., Mixed-mode fracture characterization of adhesive joints. Composites Science and Technology, 1994; 50(4): 441-9.

[5] Cox, B.N., Massabò, R., Rugg, K.L., The science and engineering of delamination suppression. In: Proceedings of the DFC6 Conference, Manchester, UK, 4-5 April 2001. 
[6] Freitas, G., Magee, C., Dardzinski P., and Fusco T., Fiber Insertion Process for Improved Damage Tolerance in Aircraft Laminates. Journal of Advanced Materials, 1994; 25(24).

[7] Grassi, M., Zhang, X., and Meo, M., Prediction of stiffness and stresses in Z-fibre reinforced composite laminates. Composites, Part A, 2002; 33: 1653-64.

[8] Cartie, D.D.R., Effect of Z-fibres on the delamination behavior of carbon fibre/epoxy laminates. PhD Thesis, Cranfield University, UK; 2000.

[9] Cartie, D.D.R., Partridge I.K., Delamination behaviour of Z-pinned laminates. In: Proceedings of the 12th International Conference on Composite Materials, ICCM12, Paris 5-9 July 1999.

[10] Troulis, M., Effect of Z-Fiber ${ }^{\circledR}$ pinning on the mechanical properties of carbon fibre/epoxy composites. PhD Thesis, Cranfield University, UK; 2004.

[11] Rugg, K.L., Cox, B.N., Ward, K.E., Sherrick, G.O., Damage mechanisms for angled throughthickness rod reinforcement in carbon-epoxy laminates. Composites, Part A, 1998;29:1603-13.

[12] Massabò, R., Cox, B.N., Concepts for bridged mode II delamination cracks. Journal of the Mechanics and Physics of Solids, 1999, 47(6):1265-1300.

[13] Cox, B.N., Sridhar, N., A traction law for inclined tows bridging mixed-mode cracks. Mechanics of Composite Materials and Structures 2002; 9: 299-331.

[14] Yan, W., Liu, H.Y., Mai, Y.W., Numerical study on the mode I delamination toughness of Zpinned laminates. Composite Science and Technology, 2003; 63: 1481-93.

[15] Yan, W., Liu, H.Y., Mai, Y.W., Mode II delamination toughness of Z-pinned laminates. Composite Science \& Technology, 2004; 64: 1937-45.

[16] Cartie, D.D.R, Partridge, I.K., A finite element tool for parametric studies of delamination in Zpinned laminates. In: Proceedings of the DFC6 Conference, Manchester, UK, 4-5 April 2001.

[17] Ratcliffe, J.G., O'Brien, T.K., Discrete spring model for predicting delamination growth in Zfiber reinforced DCB specimens. NASA/TM-2004-213019, May 2004.

[18] Grassi, M., Zhang, X., Finite element analysis of mode I interlaminar delaminations in Z-fibre reinforced composite laminates, Composite Science \& Technology, 63, (2003), 1815-32.

[19] Grassi, M., Cox, BN, Zhang, X., Simulation of pin-reinforced single-lap composite joints for optimal design. Submitted to Composite Science \& Technology, Dec 2004.

[20] Allegri, G., Zhang, X., An explicit analytical constitutive model of Z-fibre response under mode II loading. Submitted to Composite Science \& Technology, Sept 2004.

[21] Wu, G., Crocombe, A.D., Simplified finite element modelling of structural adhesive joints, Computer and Structures, 1996; 61: 385-91.

[22] Allegri, G., Zhang, X., Delamination/debond growth in z-fibre reinforced composite t-joints: a finite element simulation. In: Proceedings ECCM 11 Conference, Rhodes, Greece, June 2004.

[23] Krueger, R., "The Virtual Crack Closure Technique: history, approach and applications", NASA/CR-2002-211628, ICASE Report No. 2002-10, 2002.

\section{Appendix A: Summary of the Z-fibre constitutive model}

A.1 Shear force acting on the delamination plane

For Z-fibre response before debonding the constitutive model is described by the following equations

$$
\tau=\frac{\mathrm{k}_{\mathrm{z}} \mathrm{L}}{\lambda}\left[\frac{\cos \phi}{\cos (\phi+\psi)}-1\right]
$$




$$
\begin{gathered}
\mathrm{u}_{\mathrm{B}}=\frac{2}{3} \mathrm{~L}\left\{\sin (\phi+\psi)-\sin \phi+\frac{\mathrm{k}_{\mathrm{z}}}{\mathrm{k}_{\mathrm{x}}} \operatorname{tg}(\phi+\psi)[\cos \phi-\cos (\phi+\psi)]\right\} \\
\mathrm{T}=\mathrm{L}\left\{\mathrm{k}_{\mathrm{x}} \mathrm{u}_{\mathrm{B}}-\frac{\tau \lambda}{2} \sin (\phi+\psi)-\frac{\mathrm{k}_{\mathrm{x}} \mathrm{L}}{2}[\sin (\phi+\psi)-\sin \phi]\right\}
\end{gathered}
$$

where $\tau$ is the interfacial stress between the Z-fibre and the surrounding laminate and $\lambda$ is the pin perimeter. All other parameters in eq. (1) are presented in Figs. 1 and 2. Eq. (1) must be solved considering the rotation $\psi$ as the independent variable and thus working out the end displacement $\mathrm{u}_{\mathrm{B}}$ and the traction force $\mathrm{T}$. Before debonding the axial distributed force acting on the Z-fibre is given by

$$
\mathrm{p}=\tau \lambda \frac{\tilde{\mathrm{z}}}{\mathrm{L}}
$$

The debonding is assumed to occur instantaneously when the rotation angle $\psi$ reaches its critical value $\psi_{\mathrm{d}}$. Consequently a pull-out stage starts, during which the governing equations are:

$$
\begin{gathered}
\tau_{\mathrm{s}}=\frac{\mathrm{k}_{\mathrm{z}}\left(\mathrm{L}-\mathrm{w}_{\mathrm{sl}}\right)}{\lambda}\left(\frac{\mathrm{L}-\mathrm{w}_{\mathrm{sl}}}{\mathrm{L}+\mathrm{w}_{\mathrm{sl}}} \frac{\cos \phi}{\cos \left(\phi+\psi_{\mathrm{d}}\right)}-1\right) \\
\mathrm{u}_{\mathrm{B}}=\frac{2\left(\mathrm{~L}^{2}+\mathrm{w}_{\mathrm{sl}} \mathrm{L}+\mathrm{w}_{\mathrm{sl}}^{2}\right)}{3\left(\mathrm{~L}+\mathrm{w}_{\mathrm{sl}}\right)}\left\{\sin \left(\phi+\psi_{\mathrm{d}}\right)-\sin \phi+\right. \\
\left.+\frac{\mathrm{k}_{\mathrm{z}}}{\mathrm{k}_{\mathrm{x}}} \operatorname{tg}\left(\phi+\psi_{\mathrm{d}}\right)\left[\cos \phi-\cos \left(\phi+\psi_{\mathrm{d}}\right)\right]\right\}+\left(\frac{\mathrm{k}_{\mathrm{z}}}{\mathrm{k}_{\mathrm{x}}}-1\right) \mathrm{w}_{\mathrm{sl}} \sin \left(\phi+\psi_{\mathrm{d}}\right) \\
\mathrm{T}=\left(\mathrm{L}-\mathrm{w}_{\mathrm{sl}}\right)\left\{\mathrm{k}_{\mathrm{x}} \mathrm{u}_{\mathrm{B}}+\left(\mathrm{k}_{\mathrm{x}} \mathrm{w}_{\mathrm{sl}}-\frac{1}{2} \tau\right) \sin \left(\phi+\psi_{\mathrm{d}}\right)-\mathrm{k}_{\mathrm{x}}\left[\sin \left(\phi+\psi_{\mathrm{d}}\right)-\sin \phi\right] \frac{\left(\mathrm{L}+\mathrm{w}_{\mathrm{sl}}\right)}{2}\right\}
\end{gathered}
$$

where the $\tau_{s}$ is the frictional shear stress acting on the Z-fibre. The distributed axial force acting on the Z-fibre is now given by $p=\tau_{s} \lambda 2$. Eq. (3) must be solved considering the pull-out slip $w_{s l}$ as an independent variable, thus calculating the end displacement $u_{B}$ and the traction force $T$.

A.2 Normal force acting on the delamination plane

In this specific case, which is representative of pure mode I Z-fibre response, the Z-fibre equilibrium is governed by the axial distributed force $p$; before debonding this force depends on the interfacial stress between the Z-fibre and the surrounding laminate. Although a special variant of the model has been 
developed to model those shear stresses, the experimental evidence suggests that the pre-debonding stage of the Z-fibre response is negligible. Thus the Z-fibre equilibrium condition can be recast simply

as

$$
\mathrm{N}=\tau_{\mathrm{s}} \lambda\left(\mathrm{L}-\mathrm{w}_{\mathrm{sl}}\right)
$$

where $N$ is the normal bridging force acting on the delamination plane.

\section{Figure and Table Captions}

Table 1 T-Joint: material mechanical properties.

Table 2 Cruciform joint: material mechanical properties.

Figure 1 Displacement and forces acting on a Z-fibre.

Figure 2 Rigid kinematics of a Z-fibre.

Figure 3 Forces acting on a Z-fibre.

Figure 4 T-joint configuration.

Figure 5 Simulation results for unpinned T-joint.

Figure 6 Results of pinned T-joint $($ pin diameter $=0.28 \mathrm{~mm}$, volumetric density $=2 \%$ )

Figure 7 Results of pinned T-joint (pin diameter $=0.28 \mathrm{~mm}$, volumetric density $=4 \%$ )

Figure 8 Results of pinned T-joint (pin diameter $=0.51 \mathrm{~mm}$, volumetric density $=2 \%$ )

Figure 9 Cruciform joint configuration.

Figure 10 Results for the Cruciform joint; un-pinned and Z-fibre reinforced configuration. 


\begin{tabular}{lccccccccc}
\hline \hline Material & $\begin{array}{c}\mathbf{E}_{\mathbf{1}} \\
(\mathbf{G P a})\end{array}$ & $\begin{array}{c}\mathbf{E}_{\mathbf{2}} \\
(\mathbf{G P a})\end{array}$ & $\begin{array}{c}\mathbf{G}_{\mathbf{1 2}} \\
(\mathbf{G P a})\end{array}$ & $\mathbf{v}_{\mathbf{1 2}}$ & $\begin{array}{c}\mathbf{X}_{\mathbf{t}} \\
(\mathbf{M P a})\end{array}$ & $\begin{array}{c}\mathbf{X}_{\mathbf{c}} \\
(\mathbf{M P a})\end{array}$ & $\begin{array}{c}\mathbf{Y}_{\mathbf{t}} \\
(\mathbf{M P a})\end{array}$ & $\begin{array}{c}\mathbf{Y}_{\mathbf{c}} \\
(\mathbf{M P a})\end{array}$ & $\begin{array}{c}\text { ILSS } \\
(\mathbf{M P a})\end{array}$ \\
\hline M36/G986 & 67 & 67 & 14 & 0.05 & 855 & 600 & 855 & 600 & 71 \\
M36 & 3.5 & 3.5 & 1.3 & 0.33 & 81 & 146 & 81 & 146 & \\
Z-Fiber $^{\mathrm{TM}}$ & 115 & & & & & & & & \\
\hline \hline
\end{tabular}

Table 1: T-Joint: material mechanical properties.

\begin{tabular}{ccccccccccc}
\hline \hline Material & $\begin{array}{c}\mathbf{E}_{\mathbf{1 1}} \\
(\mathbf{G P a})\end{array}$ & $\begin{array}{c}\mathbf{E}_{\mathbf{2 2}} \\
(\mathbf{G P a})\end{array}$ & $\begin{array}{c}\mathbf{G}_{\mathbf{1 2}} \\
(\mathbf{G P a})\end{array}$ & $\mathbf{V}_{\mathbf{1 2}}$ & $\begin{array}{c}\mathbf{X t} \\
(\mathbf{M P a})\end{array}$ & $\begin{array}{c}\mathbf{X c} \\
(\mathbf{M P a})\end{array}$ & $\begin{array}{c}\mathbf{Y t} \\
(\mathbf{M P a})\end{array}$ & $\begin{array}{c}\mathbf{Y c} \\
(\mathbf{M P a})\end{array}$ & $\begin{array}{c}\mathbf{S} \\
(\mathbf{M P a})\end{array}$ & $\begin{array}{c}\text { ILSS } \\
(\mathbf{M P a})\end{array}$ \\
\hline $\mathbf{9 1 4 / G 8 0 3}$ & 71.4 & 65.7 & 49.2 & 0.05 & 590 & 590 & 400 & 400 & 111 & 67 \\
$\mathbf{9 1 4}$ & 3.9 & 3.9 & 1.4 & 0.41 & 48 & 180 & 48 & 180 & - & -
\end{tabular}

Table 2: Cruciform joint: material mechanical properties. 


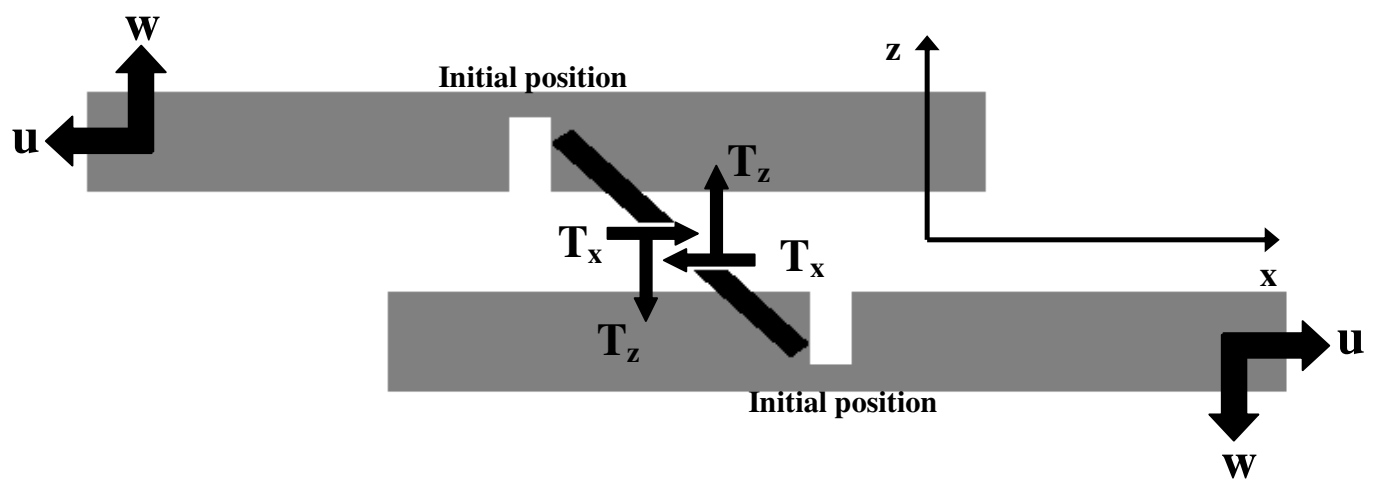

Figure 1 Displacement and forces acting on a Z-fibre.

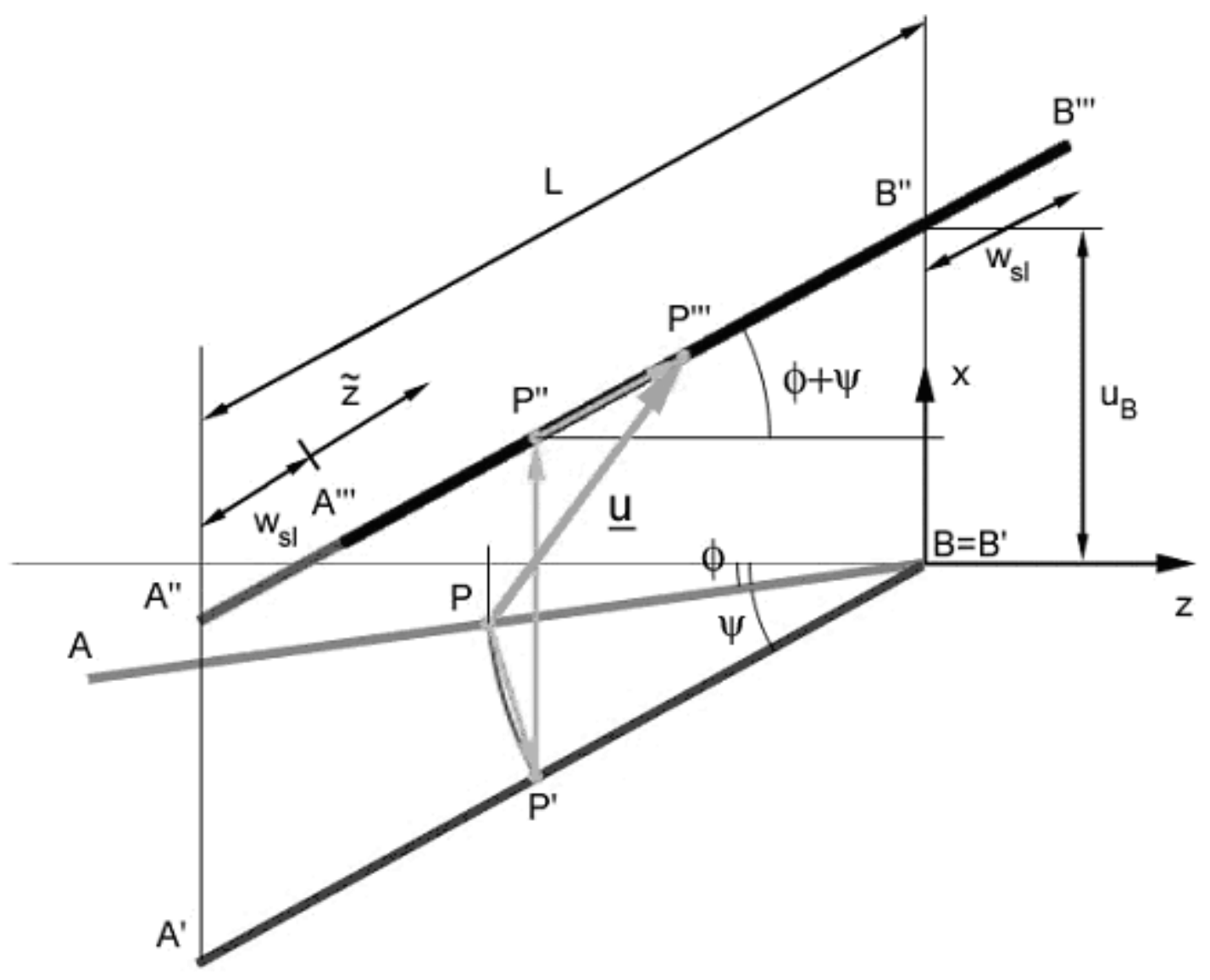

Fig. 2 Rigid kinematics of a Z-fibre 


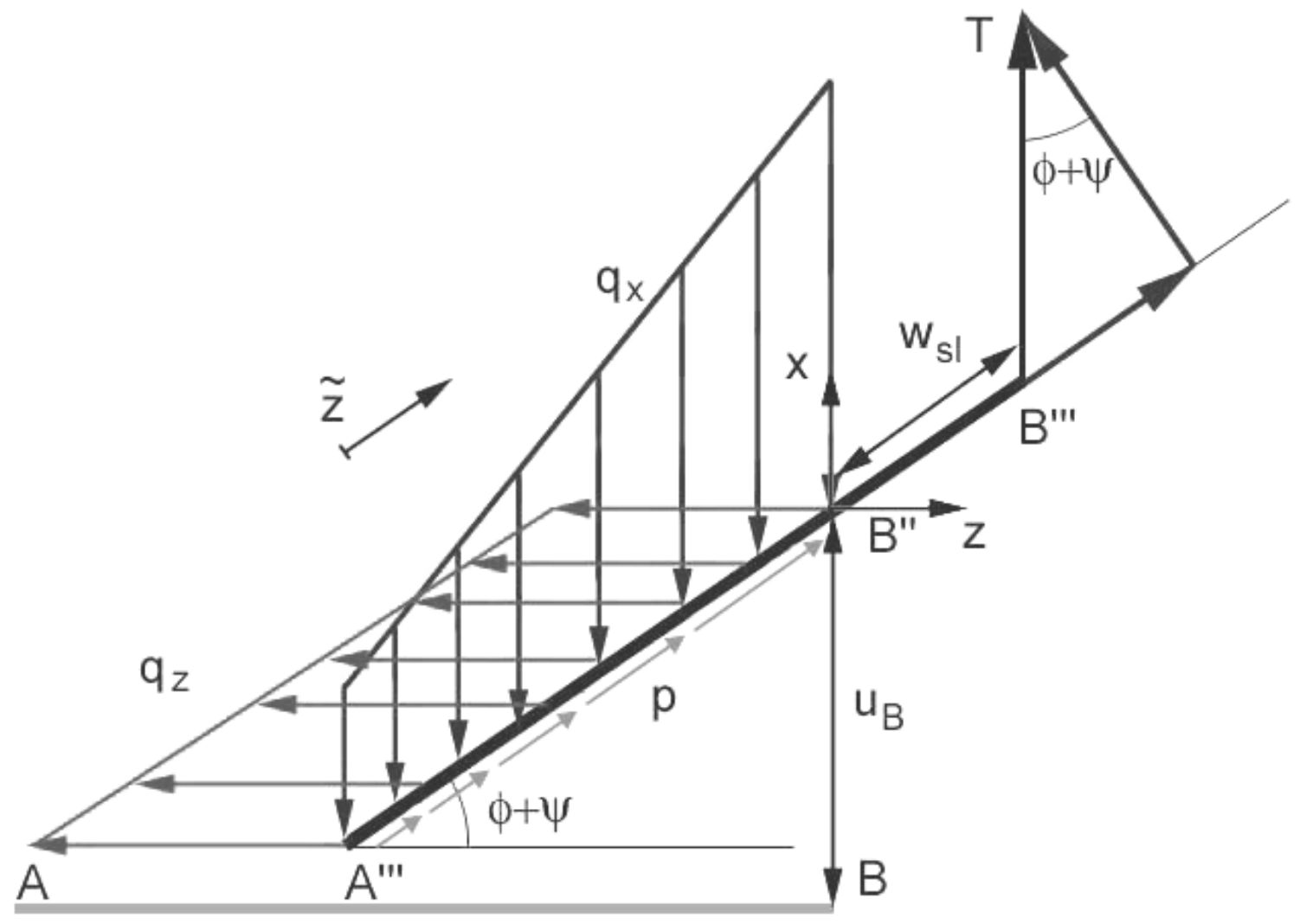

Fig. 3 Forces acting on a Z-fibre

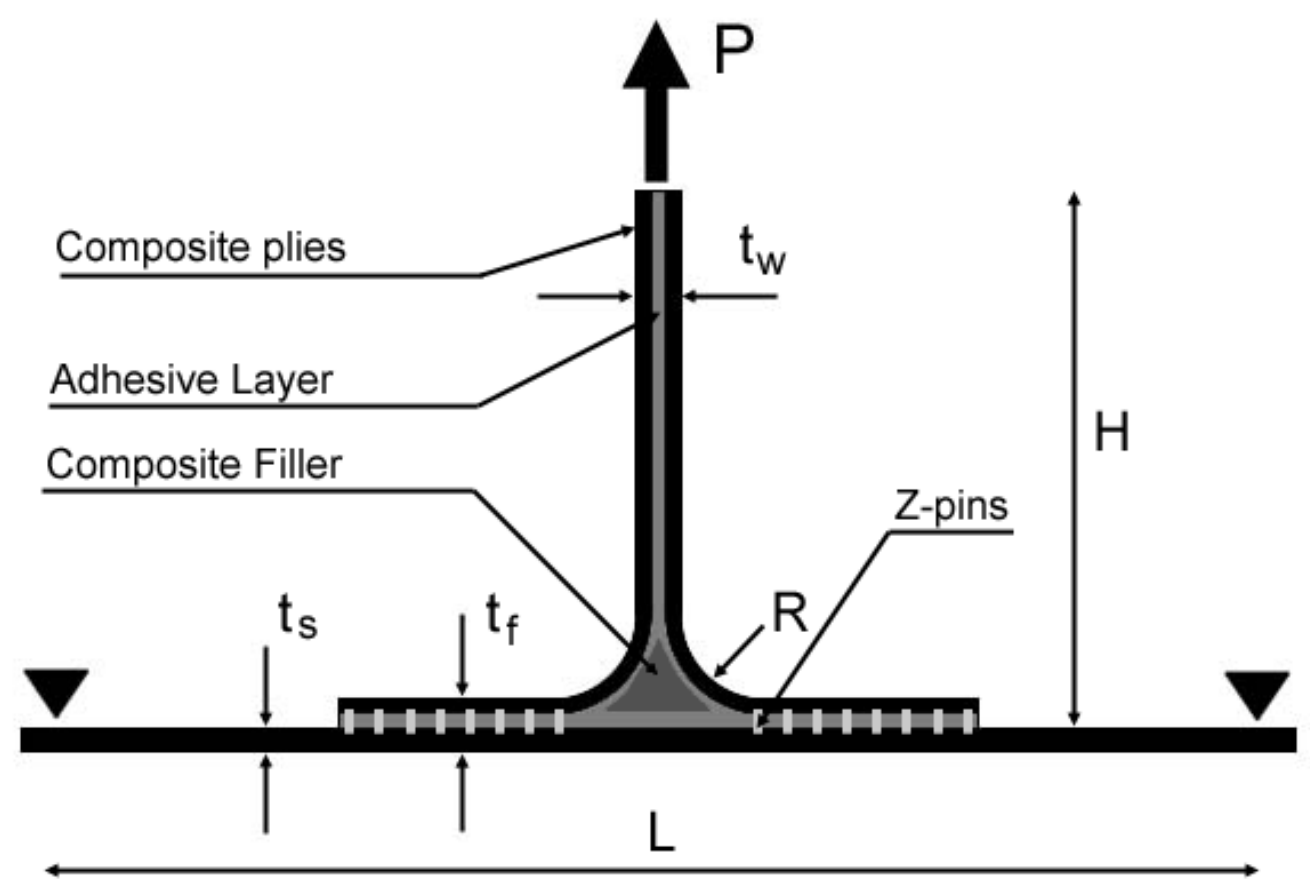

Fig. 4 T-joint configuration 


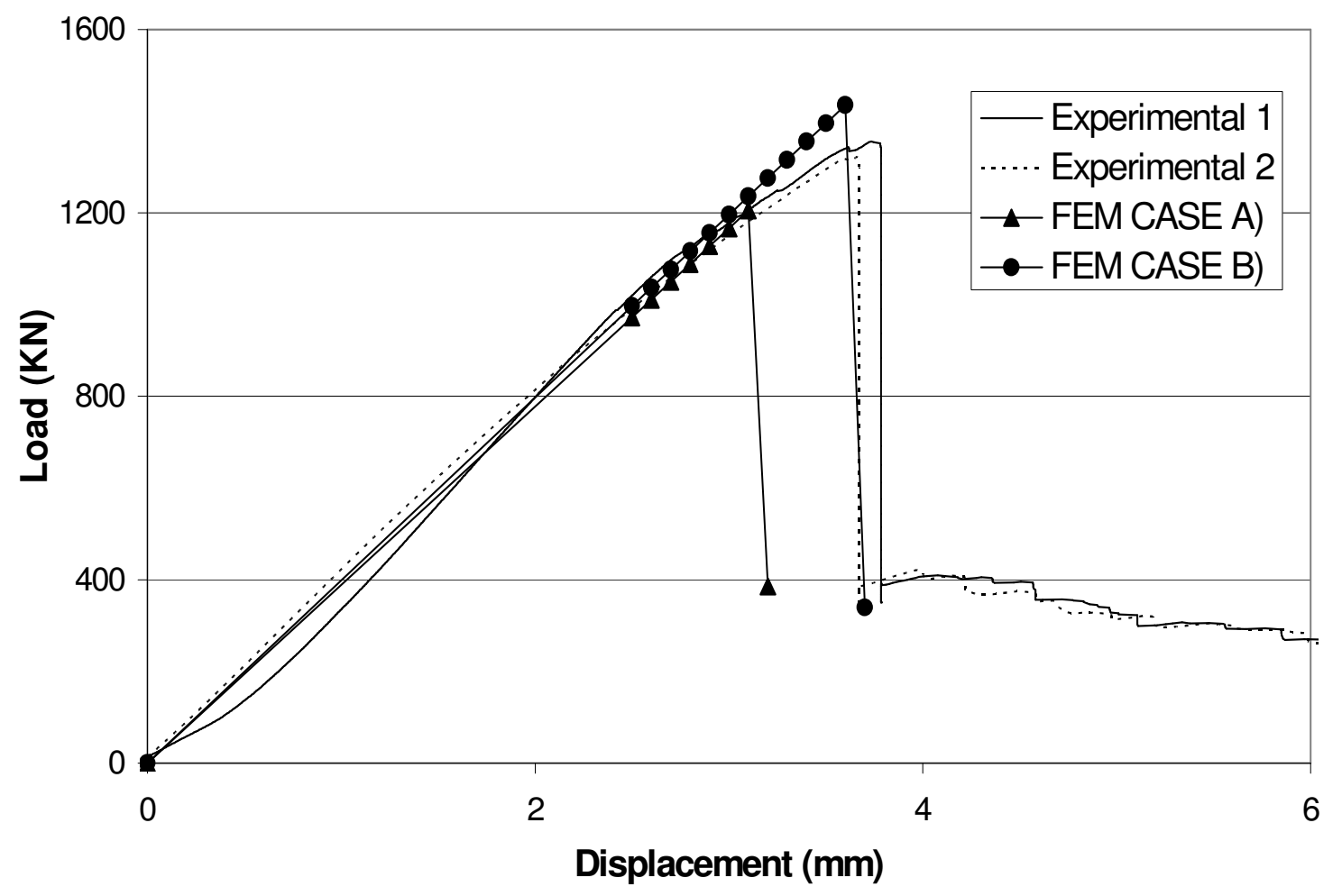

Fig. 5 Simulation results for unpinned T-joint

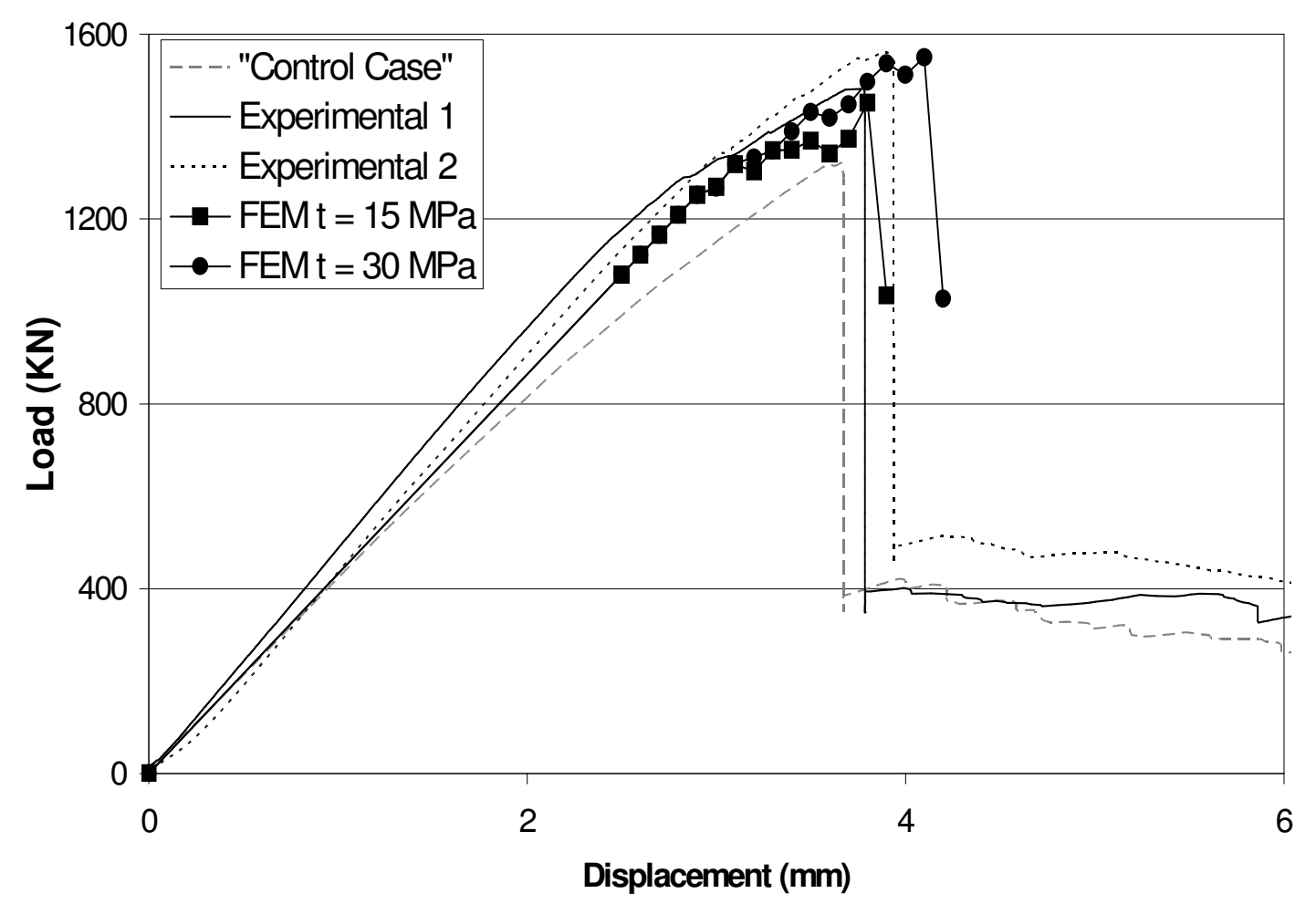

Fig. 6 Results of pinned T-joint (pin diameter $=0.28 \mathrm{~mm}$, volumetric density $=2 \%$ ) 


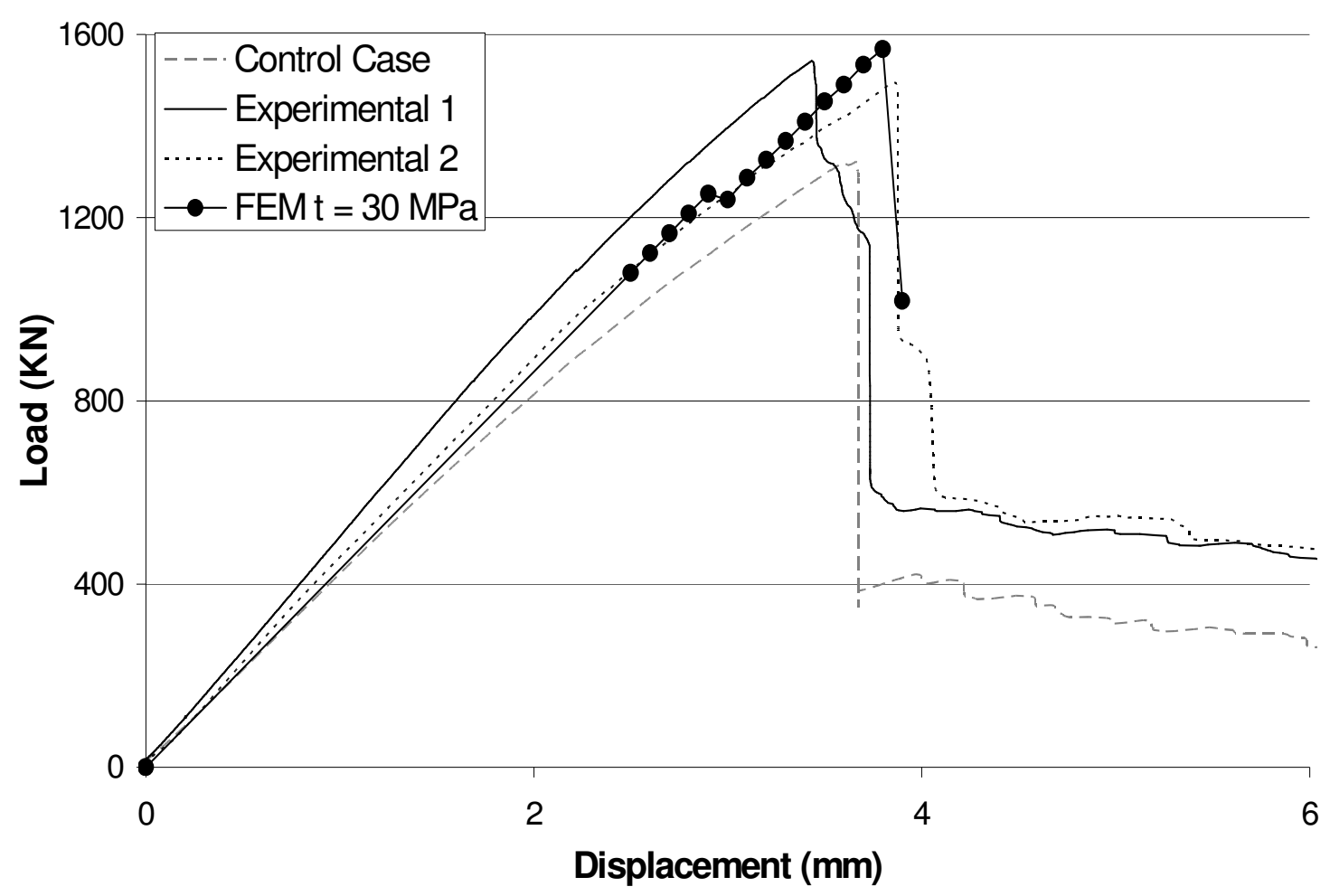

Fig. 7 Results of pinned T-joint (pin diameter $=0.28 \mathrm{~mm}$, volumetric density $=4 \%$ )

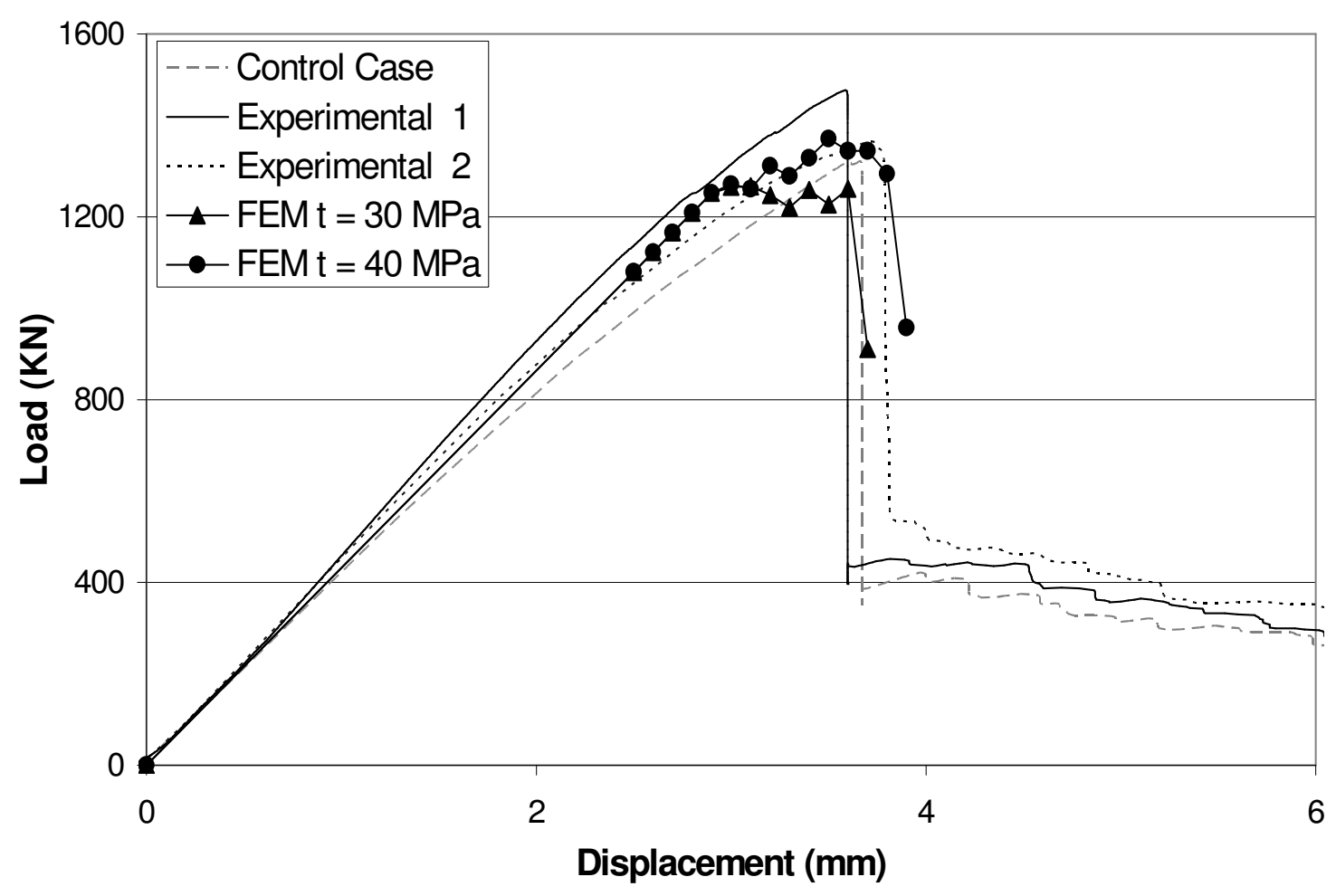

Fig. 8 Results of pinned T-joint (pin diameter $=0.51 \mathrm{~mm}$, volumetric density $=2 \%$ ) 


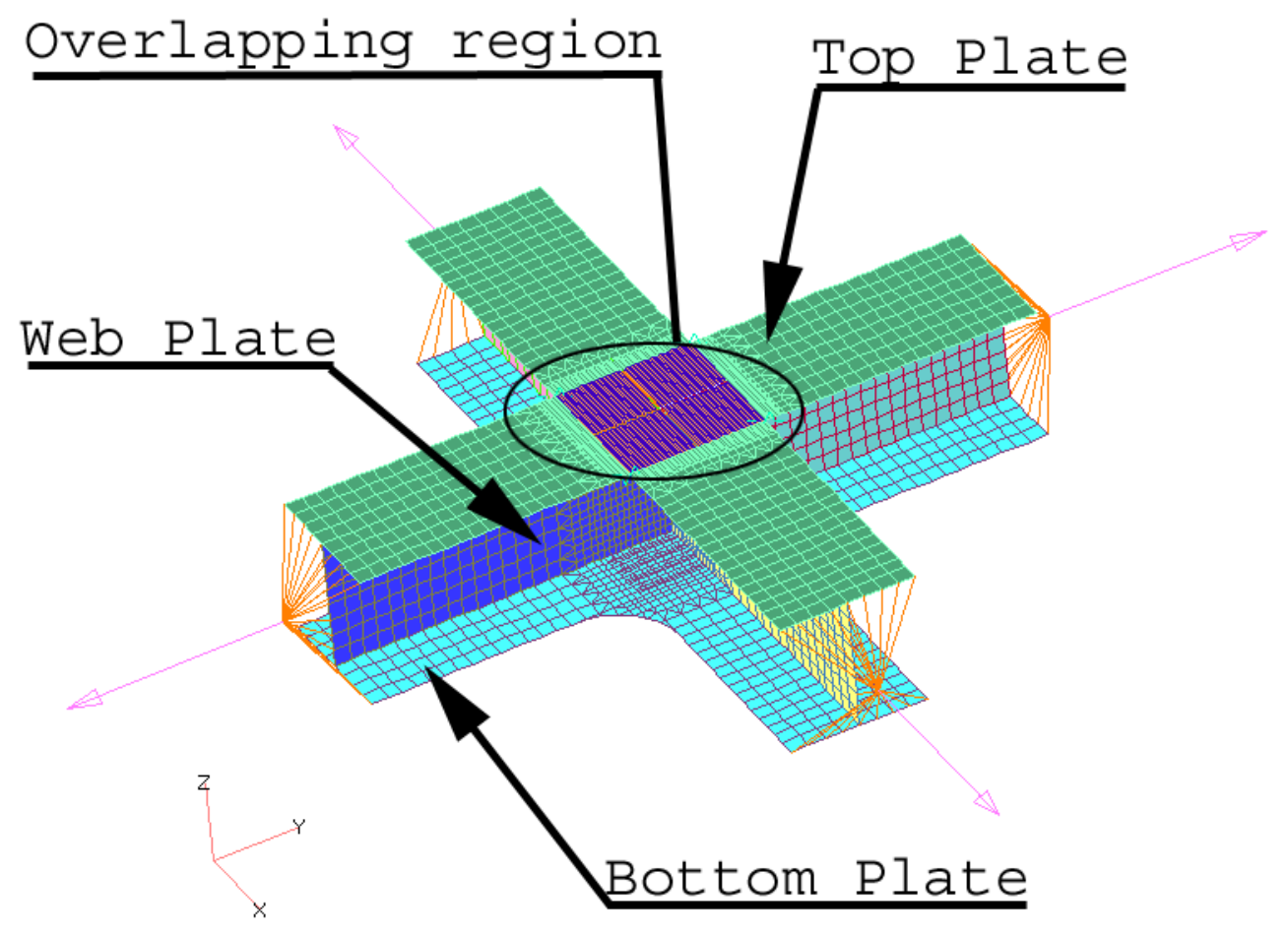

Fig. 9 Cruciform joint configuration

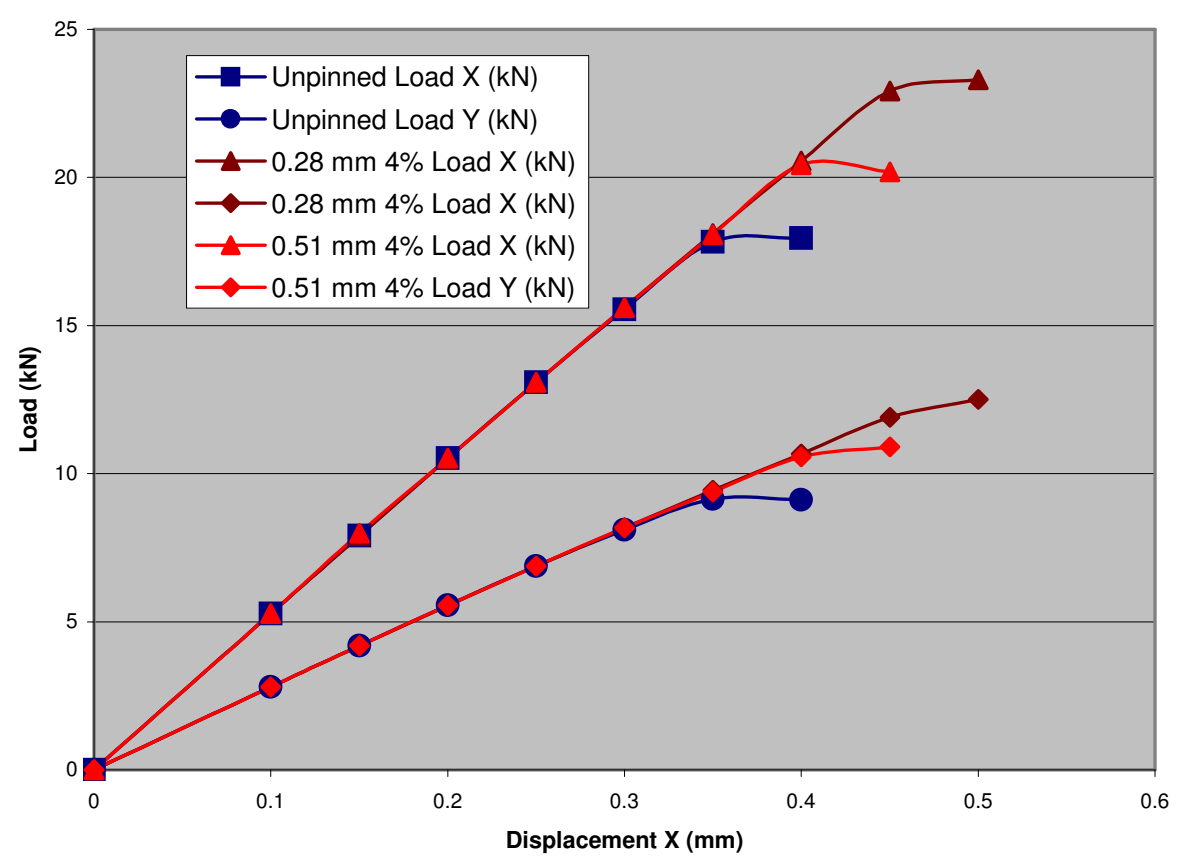

Fig. 10 Results for the cruciform joint; un-pinned and Z-fibre reinforced configuration 